Original Article

\title{
Physical and Mental Health Status of Adolescents of Government Juvenile Development Centers in Bangladesh
}

\author{
${ }^{*}$ Islam MS ${ }^{1}$, Halim KS ${ }^{2}$, Mostary KF${ }^{3}$, Muna $\mathrm{AT}^{4}$, Khan BEZ ${ }^{5}$, Nupur AS ${ }^{6}$, Saon $\mathrm{MIH}^{7}$
}

\begin{abstract}
Gradual rising of crime among adolescents is now a social and public health concern worldwide. A total of 1.9 million children getting incarcerated worldwide yearly where in Bangladesh, 1.3 million of children engaged in hazardous job most of them involved in crime. Again, physical and mental well-being is the legal and constitutional rights of the every adolescent including detained adolescent of Juvenile Development Centers. This is a cross-sectional study conducted to assess the physical and mental health status as well as socio-demographic status of adolescents of two Government Juvenile Development Center, Tongi and Konabari, Gazipur from January to December 2017. 191 adolescents were selected purposively (male: female=1.41:1). Data were collected by face to face interview and record review and height and weight of the respondents were measured. The mental health status was measured by WHO-5 Well-being Scale. The age range was from 13 to 17 years. Age of the respondents were significantly correlated with score of the WHO-5 well-being scale $(p=0.028)$. The study observed higher score among respondents who had detained here for more than 2 months which was highly significant $(p<0.001)$. Most of the respondents (75.9\%) belong to poor family. The mean score of
\end{abstract}

1. *Dr. Md. Safikul Islam, Medical Officer, Department of Epidemiology, National Institute of Preventive and Social Medicine (NIPSOM), Mohakhali, Dhaka. E-mail: safikulislamrajib01@gmail.com

2. Dr. Kazi Safiqul Halim, Associate Professor, Department of Epidemiology, (NIPSOM), Mohakhali, Dhaka.

3. Dr. Kazi Fardana Mostary, Medical Officer, Department of Epidemiology, (NIPSOM), Mohakhali, Dhaka.

4. Dr. Atiya Tasnim Muna, Department of Epidemiology, (NIPSOM), Mohakhali, Dhaka.

5. Dr. Bushra-E-Zannat Khan, Department of Epidemiology, (NIPSOM), Mohakhali, Dhaka.

6. Dr. Aklima Sadek Nupur, Medical Officer (Honorary), Dhaka Dental College, Mirpur, Dhaka.

7. Md. Istiaque Hossain Saon, Department of Theoretical and Computational Chemistry, University of Dhaka.

* For correspondence the WHO-5 well-being scale of the respondent was $52.20 \pm 10.0$, where $35.1 \%$ had good and $64.9 \%$ had poor psychological well-being status and higher among male respondents $(52.92 \pm 10.40)$ than the female respondents (51.29 \pm 9.45$)$. The respondents who were employee prior to this institution had significantly high score $(p=0.024)$. A significant relationship was observed between type of crime and the score of WHO-5 well-being scale $(p=0.003)$. The mean body mass index was $20.26 \pm 1.27 \mathrm{~kg} / \mathrm{m}^{2}$. Almost every respondent (92.7\%) belongs to normal nutritional category. Well-being score of the respondents was significantly increased with the body mass index ( $p=0.005)$. This study revealed score of WHO-5 well-being scale was significantly associated with duration of stay of the respondents $(p<0.001, R=0.540)$. Thus this study provides prevalence of mental health status and nutritional status as well as socio-demographic condition of adolescents of Government Juvenile Development Centre in Bangladesh which may provide the Government, sociologists and psychologists valid and reliable data for making plans and policies for improving or updating the living conditions of detainee of Juvenile development Centre.

Keywords: Psychological well-being, juvenile development centers in Bangladesh, adolescents.

\section{INTRODUCTION}

About 1.2 billion of adolescent constitutes 18 percent of total world population. Among them the Asia-Pacific region contains 60 percent of the adolescent population. South Asia is regarded as the home of adolescents, having around 330 million in 2009 than any other region. ${ }^{1}$ There are 29.5 million adolescents in Bangladesh; among them 14.4 million girls and 15.1 million boys, making up about one fifth of total population. ${ }^{2}$

Delinquency may refer to behavior by youths under 18 years of the age which is not acceptable to society and is generally regarded as taking some kind of admonishment, punishment or corrective action. The growing number of children is involving with the criminal activities due to industrialization which is a matter of great concern for every nation specially developing country like Bangladesh. ${ }^{3}$ 
According to Child Incarceration Statistics, total $1,900,000$ numbers of children getting incarcerated worldwide yearly; where 70,000 children remain detained on any given day. Children are involved in $25.9 \%$ of all violent offences and $74.1 \%$ of all non-violent offences worldwide. 336 in USA, 46.8 in England and Wales, 69 in South Africa, 24.9 in Australia per 1,00,000 youth population are involved in criminal activity. According to Bangladesh Bureau of Statistics, around 1.3 million children are engaged in hazardous jobs, $70 \%$ of whom are also involved in criminal activities. According to Ministry of Home Affairs, around $44 \%$ of the street children in Bangladesh are involved in drug peddling, 35\% involved in picketing, $12 \%$ in mugging, $11 \%$ in human trafficking and $21 \%$ in other criminal activities. ${ }^{4}$

The global approach for prevention and protection of juvenile offenders through administration of justice has undergone vast transformations under the auspices of the United Nations with various international rule, convention and guidelines. ${ }^{5}$ Since independence of Bangladesh in 1971, the first expression of concern about the protection of children came through the Children Act 1974. In 1990, after signing the Convention on the Rights of the Child (CRC) 1989, the law and policy has not substantially been changed which ensures that juveniles are separated and treated differently from adults and to protect their best interest during all kinds of legal processes. In practice, often the Act is not being implemented and as a result children receive the same treatment as adults. Consequently, children suffer adversely from existing laws and practices. In this context, recently, the Children Act 2013 has enacted on the basis of CRC that Bangladesh ratified 23 years ago. ${ }^{6}$

Almost in every country there is government juvenile correction or detention centre. In Bangladesh it is named as Juvenile Development Centre. They are three in numbers- two for boys and one for girls. The first Juvenile Development Centre was established in 1978 in Tongi, Gazipur for boys. Initially it had capacity for 200 boys, later the capacity was upgraded upto 300 boys. The second Juvenile Development Centre was established in Jessore in 1995 for 150 boys. The third and only Juvenile Development Centre for girls was established in Konabari, Gazipur in 2003 for 150 girls. All of these institutes involved themselves in improving their future life.

As adolescence is a period of turbulent time, a thorough understanding of adolescence in society depends on not only their biological, historical, sociological, educational or anthropological status, but also their psychological status. So this study was carried out to assess the psychological well-being status of adolescents of Juvenile Development Centers of Bangladesh.

\section{MATERIALS AND METHODS}

A cross-sectional study was conducted among the adolescents of Juvenile Development Centre, Tongi, Gazipur for boys and Konabari, Gazipur for girls. The period of study was from January to December 2017. By purposive sampling, total 191 respondents were selected. As per Children Act 2013, a Juvenile Development Centre can retain a convicted personnel upto 18 years, so 10 to 17 years was the age group of this study. A pre-tested, semi-structured questionnaire was used for data collection which contains question regarding socio-demographic status, their previous and current criminological profile and a scale named The WHO-5 Well-being Scale.

World Health Organization's Well-Being Index (WHO-5) is a short and generic global rating scale for measuring subjective well-being. It considers the five positive points of well-being for the measurement of mental health. The WHO-5 items are: 1) I have felt cheerful and in good spirits, 2) I have felt calm and relaxed, 3) I have felt active and vigorous, 4) I woke up feeling fresh and rested and 5) My daily life has been filled with things that interest me. The respondent is asked to rate how well each of the 5 statements applies to him or her when considering the last 2 weeks. Each of the five items is scored from 5 (all of the time) to 0 (none of the time). The raw score therefore ranges from 0 (absence of well-being) to 25 (maximal well-being). As because the scales measuring health related quality of life are translated to a percentage scale from 0 (absent) to 100 (maximal), the raw score is multiplied by 4 . The score below 50 is considered as poor well-being status and score 50 and above is considered as good well-being status. ${ }^{7}$

Data were collected by face to face interview and record review. Height of the respondents was measured in centimeters by measuring tape and weight in kilogram by Camry weighting machine. Substance abuse was measured by statement of the respondents.

Data were processed and analyzed by using software SPSS, version 23.0. Both descriptive and inferential analysis was done according to the objective of the study. The level of significance was set at 0.05 .

Prior to commencement of the study, the research protocol was approved by the Ethical Review Board (ERB) of National Institute of Preventive and Social Medicine (NIPSOM). The aims and objectives of the study along with its procedure, methods, risks and benefits were 
explained to the respondent in easily understandable language and then informed written consent was taken from each respondent as well as legal authority. It was assured that all information and records would be kept confidential.

\section{RESULTS}

A total 191 adolescents of Juvenile Development Centers were studied for this cross sectional type of study. Among them $55.5 \%$ were male and $44.5 \%$ were female; $95.3 \%$ were Muslims and $4.7 \%$ were Hindus; $94.8 \%$ were unmarried and $5.2 \%$ were married; $31.4 \%$ were currently on study, whereas $68.6 \%$ dropped out from the educational institute; $32.5 \%$ of father and $53.4 \%$ of mother of the respondents were not educated.

The mean age of the respondents was $15.20 \pm 1.145$ years. The respondents were categorized as poor, middle class and rich as per Asian Development Bank; ${ }^{8} 75.9 \%$ of respondents were poor and rest $24.1 \%$ were on middle class. The mean of their monthly income was $3683.88 \pm 2075.40$ BDT.

The mean of the WHO-5 well-being scale of the respondents was 52.20 \pm 9.997 . Among the respondents, $35.1 \%$ were in the category of good psychological well-being status whereas $64.9 \%$ were in poor psychological well-being status (Figure-1).

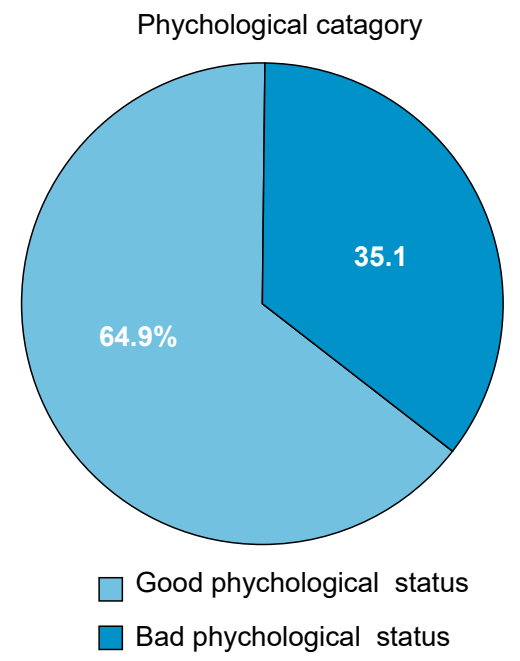

\section{Figure-1: Pie chart showing category of psychological well-being status among the respondents}

Nutritional status of the respondents was measured by their body mass index (BMI). The mean BMI of the respondents was $20.26 \pm 1.267 \mathrm{~kg} / \mathrm{m} 2 ; 92.7 \%$ of respondents were in normal, $5.2 \%$ were in underweight, $0.5 \%$ were in pre-obese and $1.6 \%$ were in overweight category (Figure-2).

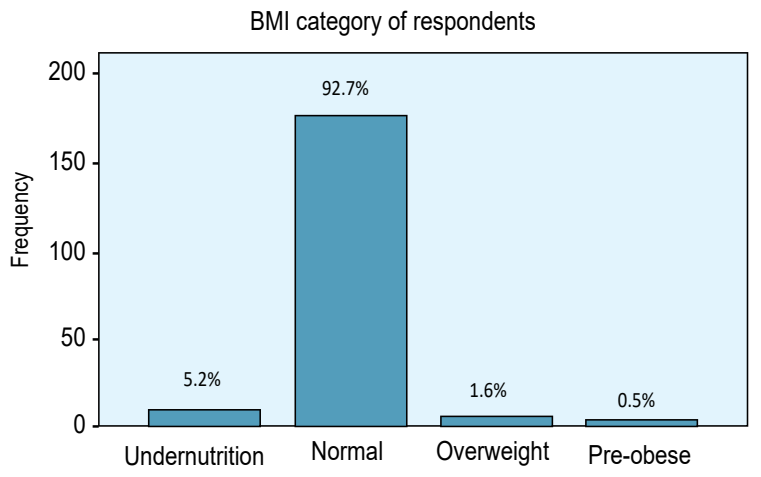

Figure-2: Histogram showing distribution of the respondents by BMI category

In the study it was found that $14.7 \%$ of respondent's family members were being victimized to any kind of assault, $28.3 \%$ of respondents thought they were deprived from their rights or property, $11.0 \%$ of respondents family member had relationship with criminal activity, $16.2 \%$ of respondents were gang member, $13.6 \%$ of respondents were influenced by their relatives or gang members on doing crime, $41.4 \%$ of respondents were involved with substance abuse.

About one third, that means $31.9 \%$ of respondents of these institute were accused for drug abuse, whereas $26.7 \%$ for assault, $19.4 \%$ for theft, $9.4 \%$ for dacoity, $7.9 \%$ for abduction, $2.1 \%$ for smuggling and rest $2.6 \%$ for murder and rape.

For the cause of doing crime, $48.2 \%$ of respondents mentioned that they are here for false allegation, $15.7 \%$ due to poverty, $12.0 \%$ due to anger, $11.5 \%$ due to frustation, $7.3 \%$ due to mental abberation and rest $5.2 \%$ due to revenge (Figure- 3 ).

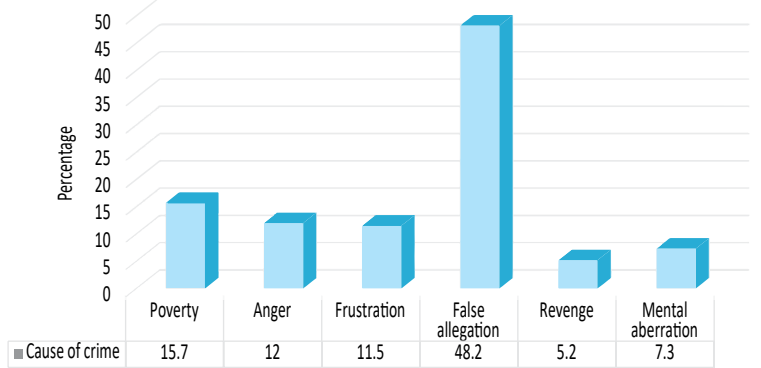

Figure-3: Distribution of the respondents by cause of doing crime

In case of inferential analysis, the dependent variable of the study, score of the WHO-5 well-being scale, was a continuous variable. So independent sample-T test and one way ANOVA was done with categorical independent variables; whereas correlation and regression was done with continuous independent variables. By analysis, it was found 
that score of the WHO-5 well-being was statistically significant with age of the respondents $(\mathrm{p}=0.028)$, duration category of the respondents $(\mathrm{p}<0.001)$, occupation of respondents prior to this institution $(p=0.024)$, type of crime respondents accused for $(\mathrm{p}=0.003)$ and BMI category of the respondents $(\mathrm{p}=0.005)$ (Table-II).

\section{Table-IV: Significant variables set}

\begin{tabular}{|l|c|c|}
\hline Variables & $\begin{array}{c}\text { Standardized } \\
\text { coefficient Beta } \\
\text { Age of the respondents }\end{array}$ & $\begin{array}{c}\mathrm{p} \\
\text { value } \\
0.118\end{array}$ \\
\hline Duration category of the respondents & 0.481 & 0.000 \\
\hline $\begin{array}{l}\text { Occupation of respondents prior to } \\
\text { this institution }\end{array}$ & -0.102 & 0.024 \\
\hline Type of crime respondents accused for & 0.060 & 0.003 \\
\hline BMI category of the respondents & -0.095 & 0.005 \\
\hline
\end{tabular}

Multiple regression was done with all the variables which were statistically significant and the result showed score of the WHO-5 well-being scale had significant association with duration category of the respondents after controlling the effect of other significant variables.

\section{DISCUSSION}

In present world, well-being as well as mental status is an well spoken term as the third goal of the Sustainable Development Goals is, "Ensure healthy lives and promote well-being for all at all ages". "For the assessment of the physical and mental status of adolescents of Government Juvenile Development Centers of Bangladesh a cross-sectional study was performed. It should be mentioned that no study was found to be conducted among adolescents of Juvenile Development Centers in Bangladesh to explore mental status before.

In this study, male-female respondent ratio was 1.41:1. According to Bangladesh Bureau of Statistics (BBS), 2016, National figure of male and female ratio is 1.003:1. Female proportion is slightly lower in this study due to shortage of time. Most of the respondents were Muslims (95.3\%) and rest were Hindus (4.7\%). According to BBS 2016, the Muslims are $89.1 \%$ and Hindus are $10 \%$. This finding of the study is slightly higher than National figure. In this study, only $31.4 \%$ of respondents were currently on education, whereas $68.6 \%$ respondents dropped out from school. According to the report of Bangladesh Bureau of Educational Information and Statistics (Banbeis) the dropout rate of children was 40.29 in 2015. So the dropout rate is more among the criminally convicted children according to this study. Male and female literacy rate was $75.62 \%$ and $69.9 \%$ respectively, according to UNESCO. From the study, it was found that, $67.5 \%$ of father and $46.6 \%$ of mother of the respondents were literate. Though the rate of literacy of father of the respondents correlates with the National figure, but literacy rate among the mother was very low. Most of the respondents (75.9\%) came from the middle class family and $24.1 \%$ came from lower class family. None of the respondent belongs to rich family. The mean monthly income of the respondents was 3683.88 BDT which was very low in compare to average monthly wages of 12897 BDT/person in Bangladesh. ${ }^{8}$

This study shows that $66.0 \%$ of the respondents thought they were never victimized to any kind of physical or mental assault. Rest of the respondents were experienced to physical or mental or both kind of assault. A study on USA shows that 5.4 million of violent crime occurred in 2014 among adolescents of age 12 and over $53 \%$ of these adolescents experienced previous physical, mental or both type of assault. ${ }^{10}$

A study conducted in South Africa among adults of type 2 Diabetes Mellitus showed 69\% of respondents were in good and $31 \%$ of respondents were in poor psychological condition by using WHO-5 well-being scale. ${ }^{11}$ This study showed, the mean score of the respondents was $52.2 \pm 10.0$. Among the respondents, $35.1 \%$ of the respondents belong to the category good psychological status, whereas $64.9 \%$ of the respondents belong to the category poor psychological status. As the study was done on adolescents and in a convicted area, the percentage of having good psychological status was lower comparing to previous study.

Body mass index (BMI) of the respondents was calculated and they were categorized according to Asian classification of nutritional status. In this study a large number of the respondents $(92.7 \%)$ had normal BMI. Underweight respondents were $5.2 \%$, overweight respondents were $1.6 \%$ and pre-obese were $0.5 \%$. This results differ from the study conducted girls in rural Bangladesh which reveals $36 \%$ girls were normal, $32 \%$ were underweight. ${ }^{12}$ As these respondents got timely diet, disciplined life style, so their nutritional status might improved from the rural girls.

Score of the WHO-5 well-being of the respondents who lived in the Juvenile Development Center for above 2 months had higher $(56.08 \pm 7.54)$ than the respondents who lived here upto 2 months $(45.63 \pm 10.24)$ which was 
highly significant $(\mathrm{p}<0.01)$. This indicate that adolescents who were the residents of Juvenile Development Center for more than 2 months got habituated with the restricted environment, adapted with the rules and terms of the institution, finds mates and had good psychological status than others.

The study result showed that age of the respondents were positively correlated with the mean score of the WHO-5 well-being scale, which was significant $(\mathrm{p}<0.05)$. Curve estimation was done and a cubic relationship was found between the age and score of the WHO-5 well-being scale. That means psychological well-being status increases with certain age limit and then decreased, which correlates with the study done in South Africa. ${ }^{11}$

\section{CONCLUSIONS}

This study provided prevalence of mental status as well as nutritional status of adolescents of Government Juvenile Development Centers in Bangladesh. Almost every respondent belong to normal BMI category. Well-being score of the respondents was significantly increased with the body mass index (BMI). Score of the WHO-5 well-being scale had significant association with duration of the respondents after controlling the effect of other significant variables. This means psychological counseling, increase sports and recreational facilities, educational and vocational services at the Government Juvenile Development Center may improve the coup-up facility of the respondents and thus improve their psychological well-being status. But the study was conducted in a small scale due to shortage of time. So, more population based researches are needed to explore physical and mental status of the adolescents of Juvenile Development Centers.

\section{REFERENCES}

1. UNICEF. Demographic trends for adolescents: Ten key facts. 2014;2.

2. Ali I. Towards a Justice Delivery System for Children in Bangladesh:A Guide and Case Law in Children in
Conflict with the Law, UNICEF, Bangladesh. 2010;17.

3. Siddique MK, Hossain MF, Kashemi F, Islam MR, Mirdha TA. Juvenile Delinquency: A Study on the Juvenile Development Centre, Tongi, Gazipur, Bangladesh. 2015;2.

4. Chowdhury S. Life Style of Street Children and Their Risk Behaviour (Dissertation), NIPSOM. 2007; 3-6.

5. Karzon, Rahman SH. Theoretical and Applied Criminology, Dhaka: Palal Prokashoni: Empowerment through Law of the Common People (ELCOP). 2008;366.

6. Ferdousi N. Juvenile Justice for the Best Interest of the Children in Bangladesh: A Legal Analysis - Journal of Law, Policy and Globalization. 2013;18: 22, 28-29.

7. Topp CW, Østergaard SD, Søndergaard S, Bech P. The WHO-5 Well-Being Index: a systematic review of the literature. Psychotherapy and psychosomatics. 2015;84(3):167-176.

8. Islam SA, Haque MI, Ahmed AM, Islam N. Bangladesh e-Journal of Sociology. 2015 Jul;12(2).

9. World Health Organization. World health statistics 2016: Monitoring health for the SDGs sustainable development goals. World Health Organization; 2016 Jun 8.

10. Cliff G, Desilets C. White collar crime: what it is and where it's going. Notre Dame JL Ethics \& Pub. Pol'y. 2014;28:481.

11. Ramkisson S, Pillay BJ, Sartorius B. Anxiety, depression and psychological well-being in a cohort of South African adults with Type 2 diabetes mellitus. South African Journal of Psychiatry. 2016;22(1):1-9.

12. Alam N, Roy SK, Ahmed T, Ahmed AS. Nutritional status, dietary intake, and relevant knowledge of adolescent girls in rural Bangladesh. Journal of health, population, and nutrition. $2010 \mathrm{Feb} ; 28(1): 86$. 